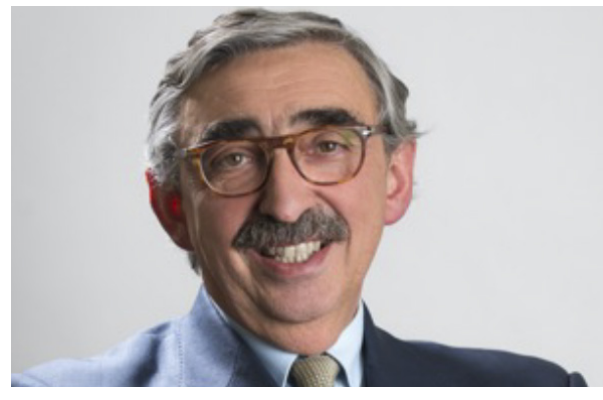

\title{
AHED - Post-Graduate, Life-Long Health Education: A Dream Coming True
}

\section{AHED - Formação Pós-Graduada, Educação ao Longo da Vida: Um Sonho a Tornar-se Realidade}

José Fragata ${ }^{1}$, Belén Vicente ${ }^{2}$

Change in healthcare is ceaseless due emerging diseases, demography, constant biomedical discoveries, new technologies for diagnosis and treatment. Also, the model of practice and management and the ever-growing society expectations contribute to this permanent scenario of change.

Professionals must keep up with the pace of innovation and the drivers for change by constantly adapting - as also recognized by World Health Organization (WHO), knowledge and competences that professionals had acquired when they graduate will need constant, life-long updating.

In fact, life-long medical education is one of professionalism's portfolio requirements and also the responsibility of each professional. Some professional boards in a few countries are already requiring their professionals to, periodically, attend post-graduate education as a pre-requisite to re-certification, in a similar way done to other high responsibility professions, as airline pilots. This obligation will also come for our doctors and health professionals in due time.

Advanced Health Education (AHED) the post-graduate school for health education was created to fulfill those needs: In 2019 a consortium formed by NOVA Medical School, José de Mello Saúde, Associação Nacional de Farmácias (ANF) and Câmara Municipal de Cascais, with the mission to provide post-graduate healthcare education in a structured manner, by high international standards, with course evaluation and credit awarding. Courses to be directed not only to medical doctors but also having in view health teams, by so involving different professionals, working together as in real life scenarios.

Courses by AHED (Advanced Health Education) traditionally focus on cutting edge technical advances, with the use of hands on, virtual or cadaveric simulation. However, courses covering classical topics are also welcome, always with a strong practical component where problem solving by attendees is encouraged.

Courses are being organized at NOVA Medical School's labs and premises, at the sophisticated simulation lab of Hospital CUF Tejo, ANF auditorium and other premises (IPO Porto, Hospital Dona Estefânia, Fundação Champalimaud, etc.), 
but a dedicated building is being constructed to soon be ready in Carcavelos, not far from NOVA's School of Business and Economics campus and, very conveniently side by side with the NOVA Medical School new premises, by so creating a health education campus.

Since its beginning, despite pandemic adversity, in 2020 AHED organized 18 courses (of 40 initial offer) enrolling 289 participants and achieving a remarkable degree of return satisfaction (net promoter score between 50 and 93!). Majority of courses (40\%) focused on multidisciplinary and integrated practice, while $30 \%$ covered pure medical topics and $30 \%$ professional practices, being more technical in nature. For 2021, 16 courses enrolling 375 participants have been concluded and another 25 are scheduled till the end of the year.

The degree of success for AHED's courses may not only be measured by the attendees' self-evaluations and net promoter scores at the end but is well expressed by the demand and avidity of the courses by growing numbers of healthcare professionals - doctors, nurses, technicians, pharmacists and everyone in the healthcare ecosystem.

AHED is run professionally: by an administration council and an academic council where courses are proposed and accepted and monitored for quality and impact. Because AHED's courses are "by NOVA Medical School", courses get also sponsored by NOVA Medical School's Scientific council, in order to further obtaining scientific validation by national academic credits. Recently, an Advisory Board is being implemented, involving industry (pharma, devices, insurers, society) in order to help the academic council in the process of courses topics selection, bridging by so our academia to the real world needs of professionals to be educated.

As an organization run by strict quality standards, AHED was granted DGERT full accreditation for educational activities, and stays ethically aligned with MedTech for activities where that is justified. Furthermore, in order to better ensure its operations, AHED already established a significant portfolio of scientifical, technical and professional cooperation with different organizations and professional societies in the field of healthcare.

AHED has already achieved its own national reputational credits as a serious school for life-long medical education, enrolling students and all an elite of top professionals in the country. More and more we foster the international market, from where we wish to attract not only students but also top professionals, that will enrich our lecturing academia.

There were many local initiatives for post-graduate medical education in the past but at AHED we, like Thomas Jefferson, "like more the dreams of the future than the history of the past". The dream is to provide every healthcare professional the education he might need, fostering professional development but, above all, contributing for better healthcare competence. This is AHED's vision \& mission, and we are getting there! 